\title{
Large pollen at high temperature: an adaptation to increased competition on the stigma?
}

\author{
Maciej Jan Ejsmond • Anna Ejsmond • Lukasz Banasiak • \\ Monika Karpińska-Kołaczek • Jan Kozłowski • Piotr Kołaczek
}

Received: 22 March 2015/Accepted: 10 September 2015/Published online: 18 September 2015

(C) The Author(s) 2015. This article is published with open access at Springerlink.com

\begin{abstract}
Pollen availability is a major constraint of plant reproductive success. Because pollen size tradesoff with the quantity of produced grains, the link between climate characteristics and the determination of pollen size is of fundamental importance. To minimize the rate of water loss due to desiccation, a plant should produce larger grains that also have a lower surface-to-volume ratio. We used a comparative analysis to examine the hypothesis predicting increase in pollen size as a response to desiccation intensity. To
\end{abstract}

Communicated by William E. Rogers.

Electronic supplementary material The online version of this article (doi:10.1007/s11258-015-0519-z) contains supplementary material, which is available to authorized users.

\section{J. Ejsmond}

Department of Arctic Biology, The University Centre in Svalbard, P.O. Box 156, 9171 Longyearbyen, Norway

M. J. Ejsmond $(\bowtie) \cdot$ A. Ejsmond · J. Kozłowski Institute of Environmental Sciences, Jagiellonian University, Gronostajowa 7, 30-387 Kraków, Poland e-mail: maciek.ejsmond@uj.edu.pl

Ł. Banasiak

Department of Molecular Phylogenetics and Evolution, Institute of Botany, University of Warsaw, Aleje

Ujazdowskie 4, 00-478 Warszawa, Poland

M. Karpińska-Kołaczek

Department of Palaeobotany and Palaeoherbarium, Jagiellonian University, Lubicz 46, 31-512 Kraków, Poland test the hypothesis, we correlated the data on pollen size with the climate characteristics, temperature and desiccation intensity of the flowering period, for 232 plant species of 11 taxonomic groups. The analysis showed a positive relationship between the pollen size and temperature, but not with the desiccation intensity. We discuss the potential mechanisms by which increased temperature is an indicator of high competition among pollen grains on the stigma, which in turn is expected to promote large pollen. Our work provides insight into the temperature dependence of pollen production in plants and reveals a link between environmental temperature and the intensity of limitation of plant reproductive success by pollen availability. The result is relevant in the context of global

\footnotetext{
M. Karpińska-Kołaczek · P. Kołaczek

Department of Biogeography and Palaeoecology, Faculty

of Geographical and Geological Science, Adam

Mickiewicz University, Dzięgielowa 27, 61-680 Poznań, Poland

M. Karpińska-Kołaczek

Laboratory of Wetland Ecology and Monitoring, Faculty of Geographical and Geological Sciences, Adam

Mickiewicz University, Dzięgielowa 27, 61-680 Poznań, Poland
} 
climate change. We also discuss why environmental temperature has to be controlled in studies dealing with pollen production, particularly in investigations of size-number trade-off.

Keywords Pollen limitation - Optimal pollen size · Temperature $\cdot$ Desiccation $\cdot$ Size-number trade-off . Competition on stigma

\section{Introduction}

Pollen limitation (PL) has been recognized as a considerable constraint of reproductive success in plants. Insufficient pollen delivery to stigmas and poor genetic quality of pollen have been proposed as two major components of PL (Aizen and Harder 2007; Ashman et al. 2004; Hegland and Totland 2008; Knight et al. 2005; Larson and Barrett 2000). The quantitative component of the concept links the reproductive performance of plants with the fundamental trade-off between size and the number of produced pollen grains. The assumption of the sizenumber trade-off is that resources available for male function are limited, and indeed, several studies confirmed that plants have to compromise between the quantity and volume of produced pollen grains (Mione and Anderson 1992; Sarkissian and Harder 2001; Vonhof and Harder 1995; Yang and Guo 2004). However, empirical support of the existence of the size-number trade-off does not explain which ecological or functional factors determine optimal combinations of size and quantity of pollen produced by a plant growing under given conditions.

The diversity of the pollen sizes produced covers a range of three orders of magnitude, which corresponds to five orders of magnitude regarding the differences in volume (Harder 1998). Such an exceptional diversity is particularly striking in light of the role of pollen size in fertilization, and the size-number trade-off outlined above has not been fully explained. Even the relation between genome size and pollen size appears to be weak when species relatedness is taken into account (see Knight et al. 2010). Certain evidence suggests that pollen size determines reproductive success at several levels. There is a strong positive relationship between pollen grain size and seed-siring success (Cruzan 1990). The size of pollen also determines the quality of the sired progeny because early fertilized ovules are more generously provisioned by the maternal plant than those that are fertilized later (Delph et al. 1998). Most importantly, large pollen grains have higher chances of success in competition and successful fertilization because their size determines the growth rate of pollen tubes (Gore et al. 1990; Lord and Eckard 1984; Manicacci and Barrett 1995; Vanbreukelen 1982). The relationship corresponds well to the positive trend between pollen size and stigma depth, which is a good measure of the distance that pollen tubes must grow using endogenous resources (Cruden 2009) or between pollen protein content and stigma-ovule distance (Roulston et al. 2000). Kirk (1993) suggested that the evolution of pollen grain size is indirectly driven by the positive selection for seed size, as this is expected to lower the number of seeds per flower and thus intensify the competition between pollen grains. In line with that, pollen size has been shown to correlate positively with seed size over a wide range of species (Kirk 1993).

Low desiccation hypothesis: under high desiccation intensity, pollen grains are large to minimize the rate of water loss

Water balance is an important issue in plant lifehistories from the earliest stage of development. Whereas different species represent a wide continuum with respect to the relative water content of produced grains (Franchi et al. 2002; Nepi et al. 2001), plant physiologists classify pollen into two types depending on the water content threshold (Firon et al. 2012). Pollen of recalcitrant type contain more than $30 \%$ water, desiccate quickly during transport and their viability dramatically decreases when the relative water content declines (Aylor 2003; Franchi et al. 2002; Nepi et al. 2001). The fate of pollen with relative water content lower than $30 \%$, denoted orthodox, is believed to be determined by their ability to keep water content at relatively low levels and, what is more important, as constant as possible during the dispersal phase (Firon et al. 2012). The viability of orthodox pollen dramatically declines, through irreversible damage to the cytoskeleton, when grains are subject to cycles of hydration and dehydration caused by fluctuations of air humidity (Heslop-Harrison and Heslop-Harrison 1992). Thus, in orthodox pollen we can also expect that natural selection promotes traits 
that decrease vulnerability to desiccation and reduce fluctuations of relative water content.

The surface-to-volume ratio is one of the major traits that determine the rate of water loss, which in turn translates to viability and chances of successful pollination (Aylor 2003; Ejsmond et al. 2011). Thus, larger grains should have an advantage over smaller ones when desiccation intensity increases. Indeed, as long as we assume that desiccation is the major force determining the viability of pollen grains, we can expect that the optimal strategy for a plant flowering under high desiccation intensity is to produce small numbers of relatively large pollen grains (Ejsmond et al. 2011). Such a tendency has been confirmed by the intraspecific analysis of pollen size of eight species of Rosaceae according to which plants flowering in conditions with high temperatures and high potential evapotranspiration (PET) produced significantly larger pollen grains than conspecifics growing at sites with lower temperatures and lower PET (Ejsmond et al. 2011).

In this paper, we test the "low desiccation" hypothesis that links the desiccation intensity of environment with the size of the pollen produced by insect-pollinated plants. Our expectation supporting the "low desiccation" hypothesis is that high PET during flowering should correlate positively with the size of produced pollen irrespective of temperature. However, the analysis must disentangle the positive correlation between temperature and PET.

\section{Materials and methods}

\section{Pollen morphology characteristics}

We extracted already published data on the mean polar $(P)$ and equatorial $(E)$ axes of pollen grains for 232 species of 11 taxonomic groups (four tribes and seven genera) published in 10 peer-reviewed articles (Table 1). We then used these measurements to calculate the mean pollen grain volume $(V)$, surface area $(S)$ and the surface-to-volume ratio $(S / V)$. For the geometrical model of a pollen grain, we chose a spheroid (i.e., ellipsoid with two equal radii, $0.5 P$, $0.5 E, 0.5 E$ ) with $S$ and $V$ calculated according to standard formulas (e.g., http://mathworld.wolfram. com/Spheroid.html, see also Supplementary material Appendix 1). All characteristics of pollen morphology used in our analysis as well as the original data that were extracted from the papers and are available in Appendix 2 in Supplementary material. In $92 \%$ of cases, a species was represented by one specimen; in the few species that were represented by two or three specimens, we analyzed the means of the pollen characteristics (given in bold in Supplementary material Appendix 2).

Assignment of coordinates to localities of the place of collection

To determine the collection site for a given specimen and assign geographical coordinates, we used descriptions of localities given in source articles or obtained from herbaria, hardcopy, and digital topographical maps (mainly maps available at The University of Texas Libraries and Google Maps) (see Supplementary material Appendix 3A, B for collection localities). We excluded all cases in which we were unable to find collection sites or the described collection site corresponded to areas with large differences in altitude (up to $500 \mathrm{~m}$ ). We also excluded all species for which the location referred to a name of an area larger than several dozen square kilometers, e.g., highlands, plains, lowlands. If the collection site was described as a place between cities and villages, we took a midpoint between the given places only in the case of a lack of considerable differences in altitude (up to $500 \mathrm{~m}$ ) and only if the distance between the mentioned places was not greater than several kilometers; otherwise, the data were excluded.

Climate conditions during flowering periods

Flowering periods for species belonging to Brunellia, Cardueae, Centaurinae, and Muscari were based on dates of specimen collection. We chose a period of 31 days ( 1 month) as a time interval for calculation of the mean temperature and PET at flowering, and the day of collection was in the middle of this period. For example, if a plant was collected on May 5, the temperature was calculated as $(5+15) / 31$ May temperature $+11 / 31$ April temperature. In two cases, i.e., Muscari coeleste and Acantholepis orientalis, only information on the month of collection was available. In such cases, we used the monthly mean for the temperature and the PET at the collection site in the analysis. We did not have collection dates for 
Table 1 General information on the species used in the study

\begin{tabular}{lllll}
\hline Taxon name & Rank & No. of species investigated & Geographic region & Source \\
\hline Brunellia & Genus & $\mathbf{1 6}(0.67)$ & South America & Orozco (2001) \\
Cardueae & Tribe & $\mathbf{1 4}(0.78)$ & Middle East, North Africa & Garnatje and Martin (2007) \\
Cayaponia & Genus & $\mathbf{2 5}(0.83)$ & Brazil & Barth et al. (2005) \\
Centaureinae & Subtribe & $\mathbf{1 6}(0.84)$ & Middle East, North Africa & Villodre and Garcia-Jacas (2000) \\
Lessingianthus & Genus & $\mathbf{6 5}(0.59)$ & South America & Angulo and Dematteis (2010) \\
Matthioleae & Tribe & $\mathbf{9}(1.00)$ & Egypt & Khalik et al. (2002) \\
Muscari & Genus & $\mathbf{1 4}(1.00)$ & Turkey & Pehlivan and Ozler (2003) \\
Mutisia & Genus & $\mathbf{2 3}(0.44)$ & South America & Telleria and Katinas (2009) \\
Sisymbrieae & Tribe & $\mathbf{9}(0.69)$ & Egypt & Khalik et al. (2002) \\
Stachys & Genus & $\mathbf{1 8}(0.62)$ & Iran & Salmaki et al. (2008) \\
Vernonia & Genus & $\mathbf{2 3}(0.96)$ & Argentina, Paraguay & Dematteis and Pire (2008) \\
\hline
\end{tabular}

Because in some cases, we were unable to assign geographic coordinates to collection sites (see. Supplementary material Appendix 2 for details), the number of analyzed species from each taxonomic group (given in bold) was also expressed as a fraction of the total number of species investigated in source articles (given in parentheses)

species belonging to Cayaponia, Lessingianthus, Matthioleae, Sisymbrieae, Stachys, Vernonia and the majority of the Mutisia specimens. For these groups, the flowering period was assessed from the literature and on-line data sources such as the Turkish Plants Data Service (http://turkherb.ibu.edu.tr), or labels of specimens of the same species as in our study that were collected in the same geographical region, which are available at herbaria on-line collections (main resource of the Missouri Botanical Garden Herbarium). The flowering periods used in the analysis were 4-month periods covering the majority of flowering dates found in literature and on-line resources. We used the following flowering periods: Matthioleae and Sisymbrieae (February-May); Stachys (May-August); Cayaponia, Lessingianthus, Mutisia, and Vernonia (4 warmest months at the collection site).

To correlate the pollen size with the climatic conditions at the collection sites, we used data on temperature and PET for corresponding places and flowering periods. The temperature and PET at flowering were calculated on the basis of the mean monthly temperature and PET during the period from 1950 to 2000 with a resolution of approximately $0.55 \times 1 \mathrm{~km}$ (Hijmans et al. 2005; Trabucco and Zomer 2009). Geographical coordinates, descriptions of the location of the collection sites, and the climate and pollen characteristics are available in Supplementary material: Appendix 2 and 3A, B. All geographic data were processed in ArcGIS 9.3 (Environmental Systems Research Institute, Redlands, USA).
Statistical analysis

To obtain one variable that best characterized both the susceptibility to desiccation and the competitive abilities of the pollen, we performed principal component analysis (PCA) for the five pollen characteristics: polar axis $(P)$, equatorial axis $(E)$, pollen grain volume $(V)$, surface area $(S)$, and surface-to-volume ratio $(S / V)$. To ensure normal distributions, $P, E, V$, and $S$ were $\log _{10}$ transformed, whereas the $S / V$ ratio was square root transformed. Because the temperature and PET were highly correlated (Pearson correlation coefficient $r=0.79, N=232$ ), we also performed PCA to obtain the independent variables best corresponding to temperature and desiccation intensity partly independent of temperature. The temperature and PET in the flowering periods were $\log _{10}$ transformed to assure normal distribution. Principal components calculated for pollen morphology were then analyzed with the general linear model (GLM) with the climate principal component as the continuous predictor and the taxonomic group as the categorical predictor. To take into account the fact that pollen morphology of different taxonomic groups can change in a different manner with climatic conditions, for each analysis, we first verified the GLM model with an interaction term included between the taxonomic group and the climate principal component. If the interaction term turned out to be non-significant, we performed a simple ANCOVA to assess the common slope characterizing the strength of the relationship. 
PCA analyses were performed with STATISTICA 10 (StatSoft, Tulsa, USA). To check the robustness of the GLM analyses, we performed Linear Mixed Model fitting with the packages nlme and lme4 implemented in R (Bates et al. 2015; Pinheiro et al. 2015; R Core Team 2015).

We also carried out a complementary analysis based on model selection and Akaike information criterion (AIC). The model selection was undertaken by fitting a series of candidate linear models, including simple regression and GLM with three predictor variables (temperature, PET, and taxonomic group) and interaction terms included. Candidate models were formulated for five dependent variables: polar axis $(P)$, equatorial axis $(E)$, pollen grain volume $(V)$, surface area $(S)$, and surface-to-volume ratio $(S / V)$. Best-fit models were indicated by lowest AIC value and highest Akaike weight $w_{i}$ providing probability that a given model is the best-fit out of all tested models (Burnham and Anderson 2004). The model selection was performed with R (R Core Team 2015).

In comparative analyses, there is a need to control for phylogenetic signal, i.e., the tendency of closely related taxonomic groups/species to resemble each other (Harvey and Pagel 1998). We were able to construct a composite phylogeny for 60 species of six taxonomic groups: Cardueae, Cayaponia, Centaureinae, Matthioleae, Mutisia, Stachys (Appendix 4 in Supplementary material), with tree topology and branch lengths, based on the outcome of genetic data analyses (for details see Appendix 1 in Supplementary material). Next, using the constructed phylogenetic tree and PDAP (Phenotypic Diversity Analysis Programs version 6.0, Garland and Ives 2000; Garland et al. 1999) we generated variance-covariance matrices used as an input for the software that fit linear statistical models. Results of ordinary (i.e., nonphylogenetic) least squares model (OLS) were compared with the results of the phylogenetic generalized least squares model (PGLS) (Garland and Ives 2000), which provide identical results and is mathematically equivalent to phylogenetic independent contrasts (Garland and Ives 2000; Rohlf 2001). Because OLS and PGLS analyses assume either no or relatively strong phylogenetic signal, we also tested two statistical models in which the strength of phylogenetic signal is estimated simultaneously with regression coefficients (Freckleton et al. 2002). These models are linear statistical models based on an Ornstein-
Uhlenbeck process of adaptive evolution (OU) and linear model with Pagel's lambda transformation (PLT) with fitted parameters $d$ (OU) and $\lambda$ (PLT). The parameters $d$ (OU) and $\lambda$ (PLT) indicate the strength of the phylogenetic signal (see Blomberg et al. 2003). In the case of both $d$ and $\lambda$, the value of 1 indicates that the original candidate tree best fits the data assuming that traits evolved according to the Brownian motion model (PLT, $\lambda$ ) or the OrnsteinUhlenbeck process of adaptive evolution (OU, $d$ ). When the parameters are close to 0 , the best-fitting evolutionary model is estimated to be a star phylogeny (no phylogenetic signal). The intermediate values between 0 and 1 indicate that branch lengths that are intermediate between the derived and a star phylogeny provide the best fit (Blomberg et al. 2003; Freckleton et al. 2002; Pagel 1999). As an indicator of the support of models fitted to the data of relatively small number of cases, we report the AICc (Akaike information criterion corrected for finite sample sizes) (Burnham and Anderson 2004; Lavin et al. 2008). When comparing a series of models the one with the lowest AICc were considered to be the best. Apart from AICc, we also present Akaike weights $\left(w_{i}\right)$ that indicate probability that a given model is the best-fit out of all tested models (Burnham and Anderson 2004). Phylogenetically informed statistical linear models were run with the program Regression 2 (Lavin et al. 2008) implemented in Matlab (MathWorks, USA). Whereas the results of the phylogenetically informed analysis were based on a phylogenetic tree with branch lengths calculated on the base of genetic distances, the conclusion did not change when branch lengths were specified by Pagel's (1992) method of branch length manipulation (not shown). Similarly, as in the case of the GLM analyses that were run on the full dataset, we performed PCA to obtain variables that best characterized both the susceptibility to desiccation and the competitive abilities of the pollen, and used these variables in phylogenetically informed analysis.

\section{Results}

The first component extracted by PCA on the base of characteristics of pollen morphology, hereafter denoted $\mathrm{PC}_{\text {poll }}$, explained $98.7 \%$ of the variance and can be interpreted as a measure of pollen size. Both axes lengths, surface area and pollen grain 
volume were positively correlated with $\mathrm{PC}_{\text {poll }}$ (factor loadings for $P, E, S$, and $V$ were greater than 0.98). Increasing $\mathrm{PC} 1_{\text {poll }}$ also corresponded with a decrease in the surface-to-volume ratio with a very high determination (factor loading for $S / V$ equal to -0.99). Two components extracted by PCA for the temperature and PET of the flowering period, $\mathrm{PC}_{\text {clim }}$ and $\mathrm{PC} 2_{\text {clim }}$, explained 89.6 and $10.4 \%$ of the variance, respectively. Increase in $\mathrm{PC} 1_{\text {clim }}$ indicated raising temperature and $\mathrm{PET}$ during flowering period accordingly (factor loadings for temperature and PET were equal to 0.95). With the increase in $\mathrm{PC} 2_{\text {clim }}$, the mean temperature of the flowering period increased while the PET decreased, as noted by the factor loadings of 0.32 for temperature and -0.32 for PET. In other words, the high value of $\mathrm{PC} 1_{\text {clim }}$ indicates places with high temperature and high PET (hot and humid), whereas high value of $\mathrm{PC} 2_{\text {clim }}$ indicates places with high temperature and low PET (hot and arid).

The analyzed taxa did not differ with the response of the pollen size described by $\mathrm{PC}_{\text {poll }}$ to PC's describing climate $\left(\mathrm{PC}_{\text {clim }} \times\right.$ taxonomic group:

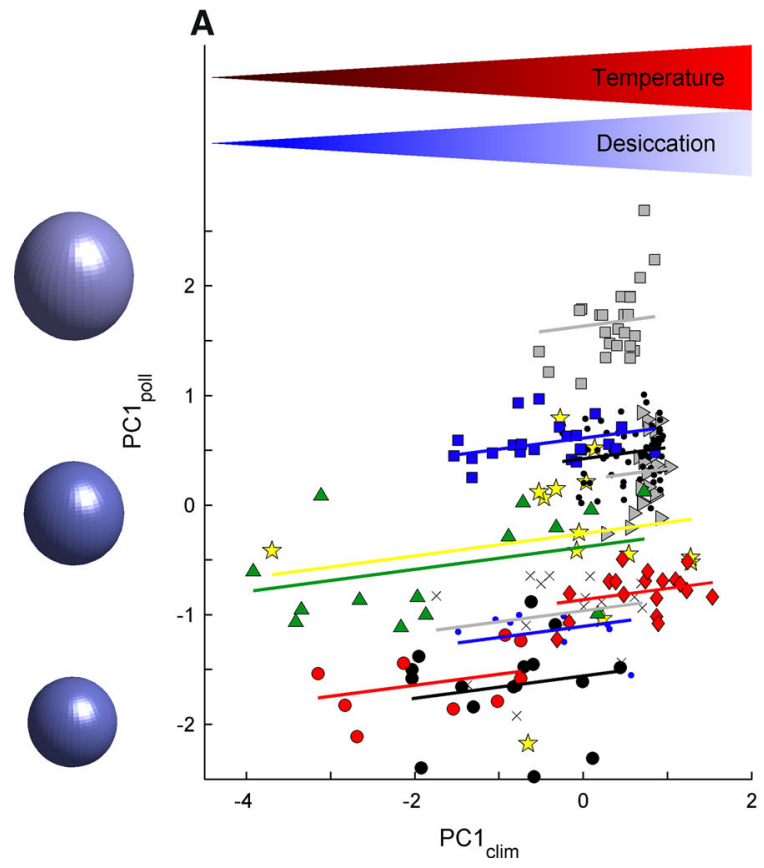

Fig. 1 The relationship between $P C 1_{\text {poll }}$, corresponding to pollen grains size and the surface-to-volume ratio, with principal components describing the climatic conditions of the flowering period. Color arrows at the top of each panel indicate the direction of the correlation between the climate principal component and temperature and desiccation intensity; high
$F_{10,210}=1.29, \quad p=0.238 ; \quad \mathrm{PC} 2_{\text {clim }} \times$ taxonomic group: $F_{10,210}=1.01, p=0.428$ ), and the interaction term was thus excluded from further analysis. $\mathrm{PC}_{\text {poll }}$ was related positively to both $\mathrm{PC} 1_{\text {clim }}$ (Fig. 1a; PC1 $\left.1_{\text {clim }}: \quad F_{1,220}=9.21, \quad p=0.003\right)$ and $\mathrm{PC} 2_{\text {clim }}$ (Fig. $1 b$; PC $2_{\text {clim }}: F_{1,220}=6.14, p=0.014$ ). Pollen size thus correlated positively with temperature at both places with PET increasing and PET decreasing with temperature, which verifies negatively the 'low desiccation hypothesis'. The relationship between $\mathrm{PC}_{\text {poll }}$ and $\mathrm{PC} 22_{\text {clim }}$ was only slightly weaker than between $\mathrm{PC} 1_{\text {poll }}$ and $\mathrm{PC} 1_{\text {clim }}$ (common slope $\pm \mathrm{SE}: 0.070 \pm$ 0.028 and $0.101 \pm 0.033$, respectively). In both cases, the taxonomic group turned out to also be a significant predictor of the intercept $(p<0.0001$ in both PC1poll vs. $\mathrm{PC} 1_{\text {clim }}$ and $\mathrm{PC}^{\text {poll }}$ vs. $\mathrm{PC} 2_{\text {clim }}$ analyses), which means that different taxa have different pollen sizes at the same value of $\mathrm{PC} 1_{\text {clim }}$ or $\mathrm{PC} 2_{\text {clim }}$ (Fig. 1a, b). Results derived with General Mixed Model fitting had qualitatively identical results with the GLM analysis (see Appendix 1 in Supplementary material for details).

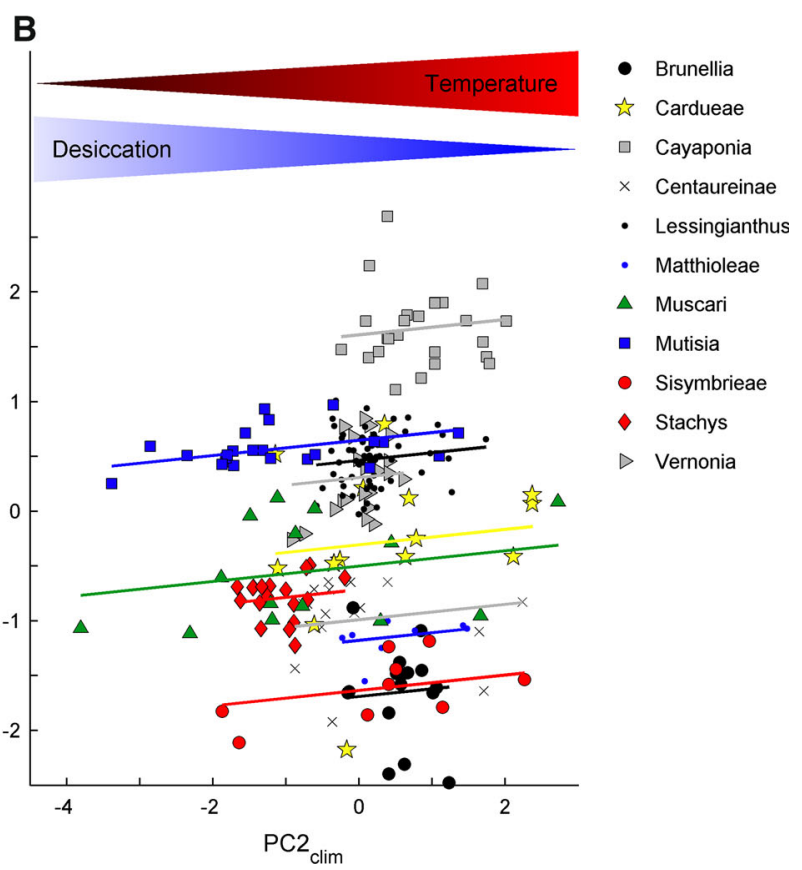

values of $\mathrm{PC} 1_{\text {clim }}$ and $\mathrm{PC} 2_{\text {clim }}$ correspond to hot-arid and hothumid climates, respectively. Because, the interaction terms of $\mathrm{PC} 1_{\text {clim }}$ and $\mathrm{PC} 2_{\text {clim }}$ with taxonomic group turned out insignificant (see "Results" section), all trend lines for taxa within each panel have a common slope. (Color figure online) 
Table 2 Summary of the model selection analysis

\begin{tabular}{|c|c|c|c|c|c|}
\hline \multirow[t]{2}{*}{ Model } & \multicolumn{5}{|c|}{ Dependent variable $Y$} \\
\hline & $S / V$ & $V$ & $S$ & $P$ & $E$ \\
\hline$Y \sim T^{*}$ & $0.00(-408.1)$ & $0.00(462.6)$ & $0.00(272.7)$ & $0.00(-75.6)$ & $0.00(-29.8)$ \\
\hline$Y \sim$ PET* $^{*}$ & $0.00(-390.7)$ & $0.00(485.4)$ & $0.00(295.3)$ & $0.00(-60.9)$ & $0.00(-3.4)$ \\
\hline$Y \sim$ taxon $*$ & $0.00(-813.8)$ & $0.00(17.0)$ & $0.00(-171.5)$ & $0.00(-472.5)$ & $0.00(-492.5)$ \\
\hline$Y \sim T^{*}+\mathrm{PET}$ & $0.00(-407.1)$ & $0.00(464.6)$ & $0.00(274.7)$ & $0.00(-73.6)$ & $0.00(-27.8)$ \\
\hline$\underline{Y} \sim \underline{T^{*}+\text { taxon }^{*}}$ & $0.40(-827.2)$ & $0.46(3.3)$ & $0.47(-185.4)$ & $0.51(-485.5)$ & $0.43(-505.8)$ \\
\hline$Y \sim$ PET + taxon* & $0.00(-814.6)$ & $0.00(15.7)$ & $0.00(-172.9)$ & $0.00(-473.9)$ & $0.00(-493.6)$ \\
\hline$\underline{Y} \simeq \underline{T^{*}+\text { PET }+ \text { taxon* }}$ & $\underline{0.57} \underline{(-827.9)}$ & $\underline{0.50} \underline{(3.1)}$ & $\underline{0.50} \underline{(-185.5)}$ & $\underline{0.47} \underline{(-485.3)}$ & $\underline{0.51} \underline{(-506.1)}$ \\
\hline$Y \sim T^{*}+\operatorname{taxon}+T \times$ taxon & $0.01(-819.1)$ & $0.01(11.0)$ & $0.01(-177.3)$ & $0.00(-484.6)$ & $0.02(-499.6)$ \\
\hline$Y \sim$ PET + taxon + PET $\times$ taxon & $0.00(-801.6)$ & $0.00(24.0)$ & $0.00(-164.2)$ & $0.00(-465.7)$ & $0.00(-484.6)$ \\
\hline$Y \sim T^{*}+\mathrm{PET}+\operatorname{taxon}^{\#}+T \times \operatorname{taxon}$ & $0.02(-820.8)$ & $0.01(11.0)$ & $0.01(-177.3)$ & $0.00(-474.1)$ & $0.02(-500.0)$ \\
\hline$Y \sim T^{*}+$ PET + taxon + PET $\times$ taxon & $0.00(-816.1)$ & $0.02(9.8)$ & $0.01(-178.3)$ & $0.01(-478.3)$ & $0.01(-498.9)$ \\
\hline
\end{tabular}

Best-fit models (underlined) are indicated by lowest AIC value (given in parentheses) and highest Akaike weight $w_{i}$ (given in italics). Akaike weights $w_{i}$ indicate probability that a given model provide the best fit out of all tested models. The statistical significance of the predictor variables is indicated by superscript symbols (see table footnotes). For all models, significant effect of a continuous climate variable ( $T$ or PET) indicate increase of $V, S, P$, and $E$ and decrease in $S / V$ with increase in the climate variable. Significant effect of taxon indicates that studied taxa differed with respect to pollen characteristics. Climate variables $T$ and PET and pollen characteristics $V, S, P, E$, were $\log _{10}$-transformed, $V / S$ was square root transformed

$* p<0.001$ for all considered $Y$ variables

\# $0.01<p<0.05$ for $S / V$ and $p>0.05$ for $V, S, P, E$

According to model selection analysis (see Table 2), inclusion of temperature, PET and taxonomic group provided the best fit for data on pollen volume $V$, surface-to-volume ratio $S / V$, surface area $S$ and equatorial axis $E$. Variation in the polar axis $P$ was best explained by temperature and taxonomic group (Table 2). In contrast to temperature, which turned out to significantly affect pollen characteristics in all models, the effect of PET was significant only when a simple regression was considered (Table 2). When significant, high temperature and PET indicated large pollen grains (high $V, S, P$ and $E$ ) with low surface-to-volume ratio $S / V$.

\section{Phylogenetically informed analysis}

The PCA run on the subset of 60 species, for which we were able to resolve the phylogeny, showed very similar pattern to PCA analyses run on the full dataset. The principal component for pollen morphology, hereafter denoted $\mathrm{PC1}_{\mathrm{p} 60}$, explained $98.6 \%$ of the variance with factor loadings for $P, E, S$ and $V$ greater than 0.98 and loading -0.99 for $S / V$. Two principal components extracted for the temperature and PET of the flowering period, $\mathrm{PC} 1_{\mathrm{c} 60}$ and $\mathrm{PC} 2_{\mathrm{c} 60}$, explained
82.3 and $17.7 \%$ of the variance, respectively. Increase in $\mathrm{PC}_{\mathrm{c} 60}$ indicated rising temperature and PET (factor loadings for temperature and PET were equal to 0.91). With the increase in $\mathrm{PC}_{\mathrm{c} 60}$, the mean temperature of the flowering period increased while the PET decreased (loading 0.42 for temperature and -0.42 for PET).

Out of four candidate models fitted in our phylogenetically informed analysis, the ordinary least squares linear model (OLS) provided the best fit with the data for both $\mathrm{PC}_{\mathrm{c} 60}$ and $\mathrm{PC} 2_{\mathrm{c} 60}$ predictor variables (Table 3 ). For models with $\mathrm{PC} 1_{\mathrm{c} 60}$ predictor variable, the OU model also showed a good fit with the data, but the value of parameter $d$ was close to 0 , which indicate a very week phylogenetic signal (Table 3). The results of model fitting showed that for the subset of 60 species, for which we were able to resolve the phylogeny, the residual variation was not explained by taking into account phylogenetic relatedness. Neither Brownian motion model of evolution (PGLS, PLT), nor adaptive evolution model (OU) provided a better fit with the data than ordinary least squares linear model (OLS). This indicates that the phylogenetic signal in the analyzed data were negligible. However, the sample size of 60 species was too little to confirm 
Table 3 Summary of the model selection in phylogenetically informed comparative analysis

\begin{tabular}{|c|c|c|c|c|}
\hline \multirow[t]{2}{*}{ Model } & \multicolumn{2}{|c|}{$\mathrm{PC}_{\mathrm{p} 60} \sim \mathrm{PC}_{\mathrm{c} 60}+$ taxon $+\mathrm{PC}_{\mathrm{c} 60} \times$ taxon } & \multicolumn{2}{|c|}{$\mathrm{PC}_{\mathrm{p} 60} \sim \mathrm{PC}_{\mathrm{c} 60}+$ taxon } \\
\hline & $\mathrm{PC} 1_{\mathrm{c} 60}$ & $\mathrm{PC} 2_{\mathrm{c} 60}$ & $\mathrm{PC}_{\mathrm{c} 60}$ & $\mathrm{PC} 2_{\mathrm{c} 60}$ \\
\hline$\underline{\text { OLS }}$ & $0.48(99.3)$ & $\underline{0.81} \underline{(98.1)}$ & $0.68(87.1)$ & $\underline{0.73}(85.0)$ \\
\hline PGLS & $0.00(152.4)^{*}$ & $0.00(164.7)$ & - & $0.00(161.1)$ \\
\hline $\mathrm{OU} \boldsymbol{d}$ & $0.43(99.5), \mathbf{0 . 0 3}$ & 0.05 (103.8), $\mathbf{0 . 0 0}$ & 0.15 (90.2), $\mathbf{0 . 0 0}$ & $0.09(89.3), \mathbf{0 . 0 0}$ \\
\hline PLT $\lambda$ & 0.09 (173.9), $\mathbf{0 . 9 1}$ & 0.15 (101.5), $\mathbf{0 . 8 8}$ & 0.17 (89.9), $\mathbf{0 . 9 0}$ & 0.18 (87.8), $\mathbf{0 . 8 8}$ \\
\hline
\end{tabular}

Best-fit models (underlined) are indicated by lowest AICc value (given in parentheses) and highest Akaike weight $w_{i}$ (given in italics). The statistical significance of the interaction term is indicated by a superscript symbol (see table footnotes). In all models with no interaction term included, the effect of climate predictor variables $\mathrm{PC}_{\mathrm{c} 60}$ on pollen morphology was not significant. The AIC and $w_{i}$ values for OU and PLT models are accompanied with the value of the fitted parameter (given in bold)

* $0.01<p<0.05$

the results obtained with GLM analyses performed for 232 species (see above). For all models fitted in our phylogenetically informed analysis, the pollen morphology was not significantly related to climate characteristics. Under the best-fit OLS models, the principal component $\mathrm{PC}_{\mathrm{p} 60}$ tended to increase with increasing values of climate principal components but the relationship was not significant (common slope \pm 95CL: $0.050 \pm 0.134$ for $\mathrm{PC}_{\mathrm{c} 60}$ and $0.139 \pm$ 0.177 for $\mathrm{PC} 2_{\mathrm{c} 60}$, OLS model).

\section{Discussion}

Our work provides evidence that interspecific variability in pollen size is affected by the environmental conditions during the flowering period. As pollen size was related to the climate principal component with opposite trends between temperature and PET, we were able to discriminate between the effects of the two interrelated environmental characteristics: temperature and desiccation intensity. The temperature explained a significant part of the variation in pollen size: large pollen grains were produced by plants growing in places with a high temperature independent of desiccation intensity. Although the surface-tovolume ratio decreased with the increase in pollen volume, we concluded that the variability in $S / V$, a primary morphological trait characterizing vulnerability to desiccation, was also explained by temperature and not desiccation stress. In other words, a lower surface-to-volume ratio at high temperature is a byproduct of selection toward large pollen and not an adaptation for high desiccation stress. The conclusion is consistent with results of model selection analysis.
Whereas temperature and PET were involved in the model providing the best fit to data on surface-tovolume ratio, only the temperature was significantly related to $S / V$. In contrast to PET, temperature was a significant predictor for both pollen size characteristics and surface-to-volume ratio in all models that provide a good fit to the data (see Table 2). The phylogenetically informed analysis run on a relatively small subsample of the full dataset (the 60 species we were able to construct phylogeny) did not confirm results from the classical statistical analyses performed on the full dataset. Overall, the results obtained do not support the 'desiccation hypothesis' proposed in our earlier work (Ejsmond et al. 2011). According to the hypothesis, plants should respond to increased desiccation intensity in the environment by producing grains that have low surface-to-volume ratio. In the previous work, we showed that at the intraspecific level, plants may produce larger pollen in response to the combined effects of temperature and desiccation (Ejsmond et al. 2011). However, we were unable to separate the effects of these two environmental characteristics, perhaps due to the relatively small geographical region considered in the study, with a relatively narrow range of PET and temperature at the collection sites (see Figure Appendix 1 in Ejsmond et al. 2011).

Temperature has to be controlled in studies on pollen production

The fundamental assumption of the expected trade-off between the size and the number of produced pollen states that the resources available for male function are limited. However, in the majority of studies in which 
the size-quantity trade-offs in pollen production were investigated, the potential diversity in the amount of resources available for a plant was not controlled for by the authors (but see Vonhof and Harder 1995). Increased temperature affects not only the size of produced pollen, as shown by our results, but is also likely to be an important determinant of the production rate in plants. Perhaps the lack of a relationship between size and the quantity of produced pollen reported by some authors (e.g., Aguilar et al. 2002; Lopez et al. 2005) can result from ignoring the effect of temperature on both pollen size and the resource pool available for male function.

Pollen size, competition on stigma

and temperature

We found that pollen size correlates with the temperature during florescence, regardless of PET. We discuss below the mechanisms given as potential explanation for the observed pattern and based on the fact, that the size determines the competitive ability of the pollen (Gore et al. 1990; Lord and Eckard 1984; Manicacci and Barrett 1995; Vanbreukelen 1982).

Pollen grain competition is expected to be strong when numerous pollen grains are competing to be the parents of only few seeds. Pollen size has been shown to correlate positively with seed size over a wide range of species. At the same time, it is hypothesized that the selection for large seeds imposes a strong competition among pollen grains, which in turn could favor larger pollen due to the larger seed size (Kirk 1993). Environmental temperature is one of the factors associated with a change in seed mass during seed plant evolution (Moles et al. 2005), and several studies based on interspecific comparative analyses provide evidence that across plant taxa, seed size increases with temperature (Dainese and Sitzia 2013; De Frenne et al. 2013; Moles et al. 2007). Thus, it is possible that the evolution of pollen grain size can be driven by the temperature-seed size dependence.

Seed size correlates with genome size in a broad range of plant taxa (Beaulieu et al. 2007). As there are several reasons why genome size and pollen size should be positively correlated, the comparative analyses based on results of phylogenetic independent contrasts did not support this hypothesis (Knight et al. 2010). We are far from understanding the mechanism driving the evolution of DNA content. Dozens of hypotheses have been proposed to explain the ultimate drivers of genome size variability observed across the tree of life (for example see Knight and Ackerly 2002; Kozłowski et al. 2003), with few influential nonadaptive hypotheses (e.g., Lynch 2007). Hence, in our opinion the role of genome size in the observed relationship between pollen size, temperature and seed size is unknown.

The foraging activity of insect floral visitors strongly depends on ambient temperature. There are studies suggesting that temperature, considered within a given plant community or an altitudinal gradient, is a strong determinant on the activity of insect pollinators and flower visitation rates (e.g., Arroyo et al. 1985; McCall and Primack 1992; Totland 2001; Wikstrom et al. 2009). The activity of hummingbirds, a second important group of pollinators, also decreases considerably at low temperatures (Elphick et al. 2001; Fernandez et al. 2002). According to this mechanism, increased temperature is an indicator of the high visitation rates of pollinators, under which the optimal strategy for a plant is to produce large grains that are able to compete with rival pollen delivered to stigmas.

The proposed mechanisms provide a link between the environmental temperature and the intensity of pollen competition, which is expected to promote the production of large pollen grains. If the strength of pollen competition rises together with temperature, we can expect a long-term change in pollen morphology towards a larger size. We can also expect intensification of PL with increasing environmental temperature.

According to the results presented, pollen size increases with temperature in several plant taxa. This suggests that pollen production and the intensity of PL can be indirectly determined by environmental temperature through the trade-off between size and the number of produced grains. The most likely explanation for the observed pattern is that the strength of the pollen competition increases with the temperature of the flowering period, which in turn is expected to promote large pollen grains.

Acknowledgments We thank H.D. Laughinghouse IV, M. Filipiak, K. Piątek, M. Czarnołęski, P. Koteja, one anonymous reviewer and C.A. Knight for valuable comments on an earlier version of this manuscript. The research was partly supported by the Foundation for Polish Science (scholarship in the frame of the 'START' for M.E.) and by Jagiellonian University (DS/ WBiNoZ/INoS 757/14). We also thank all the people who 
provided detailed descriptions of the collection sites of some of the specimens included in our study: A.P. Clark (U.S. National Herbarium, Department of Botany, Smithsonian Institute), J.C. Solomon (Missouri Botanical Garden), T. Zanoni (New York Botanical Garden), M. Assadi (Research Institute of Forests and Rangelands Herbarium) and M.C. Telleria.

Open Access This article is distributed under the terms of the Creative Commons Attribution 4.0 International License (http:// creativecommons.org/licenses/by/4.0/), which permits unrestricted use, distribution, and reproduction in any medium, provided you give appropriate credit to the original author(s) and the source, provide a link to the Creative Commons license, and indicate if changes were made.

\section{References}

Aguilar R, Bernardello G, Galetto L (2002) Pollen-pistil relationships and pollen size-number trade-off in species of the tribe Lycieae (Solanaceae). J Plant Res 115:335-340

Aizen MA, Harder LD (2007) Expanding the limits of the pollen-limitation concept: effects of pollen quantity and quality. Ecology 88:271-281

Angulo MB, Dematteis M (2010) Pollen morphology of the South American genus Lessingianthus (Vernonieae, Asteraceae) and its taxonomic implications. Grana 49:12-25

Arroyo MTK, Armesto JJ, Primack RB (1985) Community studies in pollination ecology in the high temperate andes of central Chile. II. Effect of temperature on visitation rates and pollination possibilities. Plant Syst Evol 149:187-203

Ashman TL, Knight TM, Steets JA, Amarasekare P, Burd M, Campbell DR, Dudash MR, Johnston MO, Mazer SJ, Mitchell RJ, Morgan MT, Wilson WG (2004) Pollen limitation of plant reproduction: ecological and evolutionary causes and consequences. Ecology 85:2408-2421

Aylor DE (2003) Rate of dehydration of corn (Zea mays L.) pollen in the air. J Exp Bot 54:2307-2312

Barth OM, Da Luz CFP, Gomes-Klein VL (2005) Pollen morphology of Brazilian species of Cayaponia silva Manso (Cucurbitaceae, Cucurbiteae). Grana 44:129-136

Bates D, Maechler M, Bolker B, Walker S (2015) lme4: linear mixed-effects models using Eigen and S4. R package version 1.1-9. https://CRAN.R-project.org/package=lme4

Beaulieu JM, Moles AT, Leitch IJ, Bennett MD, Dickie JB, Knight CA (2007) Correlated evolution of genome size and seed mass. New Phytol 173:422-437

Blomberg SP, Garland T, Ives AR (2003) Testing for phylogenetic signal in comparative data: behavioral traits are more labile. Evolution 57:717-745

Burnham KP, Anderson DR (2004) Multimodel inference: understanding AIC and BIC in model selection. Sociol Methods Res 33:261-304

Cruden RW (2009) Pollen grain size, stigma depth, and style length: the relationships revisited. Plant Syst Evol 278:223-238

Cruzan MB (1990) Variation in pollen size, fertilization ability, and Postfertilization siring ability in Erythronium grandiflorum. Evolution 44:843-856
Dainese M, Sitzia T (2013) Assessing the influence of environmental gradients on seed mass variation in mountain grasslands using a spatial phylogenetic filtering approach. Perspect Plant Ecol Evol Syst 15:12-19

De Frenne P, Graae BJ, Rodriguez-Sanchez F, Kolb A, Chabrerie O, Decocq G, De Kort H, De Schrijver A, Diekmann M, Eriksson O, Gruwez R, Hermy M, Lenoir J, Plue J, Coomes DA, Verheyen K (2013) Latitudinal gradients as natural laboratories to infer species' responses to temperature. J Ecol 101:784-795

Delph LF, Weinig C, Sullivan K (1998) Why fast-growing pollen tubes give rise to vigorous progeny: the test of a new mechanism. Proc R Soc B Biol Sci 265:935-939

Dematteis M, Pire SM (2008) Pollen morphology of some species of Vernonia s. 1. (Vernonieae, Asteraceae) from Argentina and Paraguay. Grana 47:117-129

Ejsmond MJ, Wrońska-Pilarek D, Ejsmond A, Dragosz-Kluska D, Karpińska-Kołaczek M, Kołaczek P, Kozłowski J (2011) Does climate affect pollen morphology? Optimal size and shape of pollen grains under various desiccation intensity. Ecosphere 2:1-15. doi:10.1890/ES1811-00147. 00141

Elphick C, Dunning JB, Sibley DA (2001) The sibley guide to bird life and behavior. Alfred A. Knopf, New York

Fernandez MJ, Lopez-Calleja MV, Bozinovic F (2002) Interplay between the energetics of foraging and thermoregulatory costs in the green-backed firecrown hummingbird Sephanoides sephaniodes. J Zool (London) 258:319-326

Firon N, Nepi M, Pacini E (2012) Water status and associated processes mark critical stages in pollen development and functioning. Ann Bot (London) 109:1201-1213

Franchi GG, Nepi M, Dafni A, Pacini E (2002) Partially hydrated pollen: taxonomic distribution, ecological and evolutionary significance. Plant Syst Evol 234:211-227

Freckleton RP, Harvey PH, Pagel M (2002) Phylogenetic analysis and comparative data: a test and review of evidence. Am Nat 160:712-726

Garland T, Ives AR (2000) Using the past to predict the present: confidence intervals for regression equations in phylogenetic comparative methods. Am Nat 155:346-364

Garland T, Midford PE, Ives AR (1999) An introduction to phylogenetically based statistical methods, with a new method for confidence intervals on ancestral values. Am Zool 39:374-388

Garnatje T, Martin J (2007) Pollen studies in the genus Echinops L. and Xeranthemum group (Asteraceae). Bot J Linn Soc 154:549-557

Gore PL, Potts BM, Volker PW, Megalos J (1990) Unilateral crossincompatibility in Eucalyptus: the case of hybridisation between E. globulus and E. nitens. Aust J Bot 38:383-394

Harder LD (1998) Pollen-size comparisons among animal-pollinated angiosperms with different pollination characteristics. Biol J Linn Soc 64:513-525

Harvey PH, Pagel MD (1998) The comparative method in evolutionary biology. Oxford University Press, Oxford

Hegland SJ, Totland $\varnothing$ (2008) Is the magnitude of pollen limitation in a plant community affected by pollinator visitation and plant species specialisation levels? Oikos 117:883-891

Heslop-Harrison J, Heslop-Harrison Y (1992) Cyclical transformations of the actin cytoskeleton of hyacinth pollen 
subjected to recurrent vapour-phase hydration and dehydration. Biol Cell (Paris) 75:245-252

Hijmans RJ, Cameron SE, Parra JL, Jones PG, Jarvis A (2005) Very high resolution interpolated climate surfaces for global land areas. Int J Climatol 25:1965-1978

Khalik KA, van der Maesen LJG, Koopman WJM, van den Berg RG (2002) Numerical taxonomic study of some tribes of Brassicaceae from Egypt. Plant Syst Evol 233:207-221

Kirk WDJ (1993) Interspecific size and number variation in pollen grains and seeds. Biol J Linn Soc 49:239-248

Knight CA, Ackerly DD (2002) Variation in nuclear DNA content across environmental gradients: a quantile regression analysis. Ecol Lett 5:66-76

Knight TM, Steets JA, Vamosi JC, Mazer SJ, Burd M, Campbell DR, Dudash MR, Johnston MO, Mitchell RJ, Ashman TL (2005) Pollen limitation of plant reproduction: pattern and process. Annu Rev Ecol Evol Syst 36:467-497

Knight CA, Clancy RB, Gotzenberger L, Beaulieu JM, Dann L (2010) On the relationship between pollen size and genome size. J Bot 2010:1-7. doi:10.1155/2010/612017

Kozłowski J, Konarzewski M, Gawełczyk AT (2003) Cell size as a link between noncoding DNA and metabolic rate scaling. Proc Natl Acad Sci USA 100:14080-14085

Larson BMH, Barrett SCH (2000) A comparative analysis of pollen limitation in flowering plants. Biol J Linn Soc 69:503-520

Lavin SR, Karasov WH, Ives AR, Middleton KM, Garland T (2008) Morphometrics of the avian small intestine compared with that of nonflying mammals: a phylogenetic approach. Physiol Biochem Zool 81:526-550

Lopez HA, Anton AM, Galetto L (2005) Pollen-pistil size correlation and pollen size-number trade-off in species of Argentinian Nyctaginaceae with different pollen reserves. Plant Syst Evol 256:69-73

Lord EM, Eckard KJ (1984) Incompatibility between the dimorphic flowers of Collomia grandiflora, a Cleistogamous Species. Science 223:695-696

Lynch M (2007) The frailty of adaptive hypotheses for the origins of organismal complexity. Proc Natl Acad Sci 104:8597-8604

Manicacci D, Barrett SCH (1995) Stamen elongation, pollen size, and siring ability in Tristylous Eichhornia paniculata (Pontederiaceae). Am J Bot 82:1381-1389

McCall C, Primack RB (1992) Influence of flower characteristics, weather, time of day, and season on insect visitation rates in three plant communities. Am J Bot 79:434-442

Mione T, Anderson GJ (1992) Pollen-ovule ratios and breeding system evolution in solanum section Basarthrum (Solanaceae). Am J Bot 79:279-287

Moles AT, Ackerly DD, Webb CO, Tweddle JC, Dickie JB, Pitman AJ, Westoby M (2005) Factors that shape seed mass evolution. Proc Natl Acad Sci USA 102:10540-10544

Moles AT, Ackerly DD, Tweddle JC, Dickie JB, Smith R, Leishman MR, Mayfield MM, Pitman A, Wood JT, Westoby M (2007) Global patterns in seed size. Glob Ecol Biogeogr 16:109-116
Nepi M, Franchi GG, Pacini E (2001) Pollen hydration status at dispersal: cytophysiological features and strategies. Protoplasma 216:171-180

Orozco CI (2001) Pollen morphology of Brunellia (Brunelliaceae) and related taxa in the Cunoniaceae. Grana 40:245-255

Pagel MD (1992) A method for the analysis of comparative data. J Theor Biol 156:431-442

Pagel M (1999) Inferring the historical patterns of biological evolution. Nature 401:877-884

Pehlivan S, Ozler H (2003) Pollen morphology of some species of Muscari Miller (Liliaceae-Hyacinthaceae) from Turkey. Flora 198:200-210

Pinheiro J, Bates D, DebRoy S, Sarkar D, R Core Team (2015) nlme: linear and nonlinear mixed effects models. R package version 3.1-122. http://CRAN.R-project.org/package= nlme

R Core Team (2015) A language and environment for statistical computing. R Foundation for Statistical Computing, Vienna

Rohlf FJ (2001) Comparative methods for the analysis of continuous variables: geometric interpretations. Evolution 55:2143-2160

Roulston TH, Cane JH, Buchmann SL (2000) What governs protein content of pollen: pollinator preferences, pollenpistil interactions, or phylogeny? Ecol Monogr 70:617-643

Salmaki Y, Jamzad Z, Zarre S, Brauchler C (2008) Pollen morphology of Stachys (Lamiaceae) in Iran and its systematic implication. Flora 203:627-639

Sarkissian TS, Harder LD (2001) Direct and indirect responses to selection on pollen size in Brassica rapa L. J Evol Biol $14: 456-468$

Telleria MC, Katinas L (2009) New insights into the pollen morphology of the genus Mutisia (Asteraceae, Mutisieae). Plant Syst Evol 280:229-241

Totland Ø (2001) Environment-dependent pollen limitation and selection on floral traits in an alpine species. Ecology 82:2233-2244

Trabucco A, Zomer RJ (2009) Global aridity index (globalaridity) and global potential evapo-transpiration (globalPET) geospatial database. CGIAR consortium for spatial information. http://www.csi.cgiar.org/

Vanbreukelen EWM (1982) Competition between 2x and $\mathrm{x}$ pollen in styles of Solanum tuberosum determined by a quick in vivo method. Euphytica 31:585-590

Villodre JM, Garcia-Jacas N (2000) Pollen studies in subtribe Centaureinae (Asteraceae): the Jacea group analysed with electron microscopy. Bot J Linn Soc 133:473-484

Vonhof MJ, Harder LD (1995) Size-number trade-offs and pollen production by Papilionaceous Legumes. Am J Bot 82:230-238

Wikstrom L, Milberg P, Bergman KO (2009) Monitoring of butterflies in semi-natural grasslands: diurnal variation and weather effects. J Insect Conserv 13:203-211

Yang CF, Guo YH (2004) Pollen size-number trade-off and pollen-pistil relationships in Pedicularis (Orobanchaceae). Plant Syst Evol 247:177-185 